\title{
Chapter 9 \\ The Influence of Technology \\ on the Mathematical Modelling of Physical Phenomena
}

\author{
Miriam Ortega, Luis Puig and Lluís Albarracín
}

\begin{abstract}
A study is presented in which students are asked to model two physical phenomena using applications on electronic tablets: a bounce of a ball and the extension of a spring. The analysis focusses on (a) the influence of characteristics of the applications on the tablets on the decisions that groups of 16-year-old students made during the modelling phases in which reality and mathematics are related, (b) mathematisation of the phenomena and (c) interpretation of the models. The phenomena were recorded using an app that requests users establish a set of references during the mathematisation process, which makes students focus on the way the references have been set to interpret the model properly. Our findings indicated inconsistences between student decisions made during mathematisation and their considerations during interpretation of the model. To conclude we suggest reasons students experience problems in working without a pre-defined reference system.
\end{abstract}

Keywords Mathematisation $\cdot$ Physical phenomena $\cdot$ Real data $\cdot \mathrm{iPad} \cdot$ Interpretation $\cdot$ Bounce of a ball $\cdot$ Lengthening of spring

\subsection{Introduction}

Usually, content in most upper secondary mathematics lessons is worked on in a formal and abstract way and students find difficulties in relating mathematical content

\author{
M. Ortega $(\varangle) \cdot$ L. Puig \\ Universitat de València Estudi General, Valencia, Spain \\ e-mail: miriam.ortega@uv.es \\ L. Puig \\ e-mail: luis.puig@uv.es \\ L. Albarracín
}

Facultat d'Educació, Departament de Didàctica de la Matemàtica i de les Ciències Experimentals, Universitat Autònoma de Barcelona, Edifici G, despatx 140 Campus de la UAB, 08193 Bellaterra (Cerdanyola del Vallès), Barcelona, Spain

e-mail: 1luis.albarracin@uab.cat 
to real-life situations (Henn 2007; Oliveira and Barbosa 2013). Many investigators (e.g. Greefrath and Siller 2017; Sala et al. 2017) have found that modelling tasks are a useful resource to show students the capability of mathematics to describe reality. In addition, the use of technology in classrooms can contribute positively to students' understanding of the phenomena in the world around us (Henn 2007; Stillman 2007). However, as Grigoraş et al. (2011) point out, "deeper analyses of the modelling situations are necessary to understand the interplay of tasks, techniques, technology and theories in modelling situations" (p. 94).

We designed teaching material for the concept of function in which two physical phenomena have to be modelled by using technological tools with the purpose of finding possible solutions to help students overcome the difficulties that may appear in relating the characteristics of functions to real phenomena. In this chapter we present a study where the influence of a technological tool on the students' decisions is analysed during the translations between the real world and mathematics.

\subsection{Theoretical Framework}

As Freudenthal (1961) already mentioned decades ago, there are many different ways of understanding the term, modelling, depending on the perspective from which we want to formalize or organize a real situation or phenomenon. From the didactics of experimental scientific disciplines and specifically from the didactical framework of scientific practice (Osborne 2014), modelling is conceived as a way of organizing physical phenomena taking into account the values of the physical magnitudes in order to shape scientific knowledge and scientific practices (Duschl and Grandy 2012). However, from a mathematical point of view, when modelling a phenomenon mathematically is concerned, we focus our interest on the mathematical content and processes that allow us to organize this phenomenon (Freudenthal 1983), which is the perspective that we adopt in our study. From this point of view, every mathematical modelling task requires translations between reality and mathematics, where reality is taken to be the rest of the world, other than the mathematical domain.

Parts of the modelling process can be described by the so-called modelling cycle, which can be guided by the questions posed in the task or promoted by the students themselves. There are several versions and interpretations of the modelling cycle (Perrenet and Zwaneveld 2012) but all start from the division proposed by Pollak (1979) in which modelling processes are studied by differentiating reality from the mathematical domain, even if we conceived of mathematics as part of the real world because reality is understood as the rest of the real world, that is the extramathematical aspects. In this way, under any of the theoretical perspectives adopted to study the modelling processes, several phases can be distinguished, among these, the transition from reality to the constructed mathematical model, that is, mathematisation, and the interpretation of the results, obtained in the mathematical domain, from the point of view of the real phenomenon studied. 
Studies involving modelling tasks with the use of technology have shown that technology related activity takes place during all phases of the modelling cycle (Geiger et al. 2010; Greefrath and Rieß 2013). Research in the frame of the instrumental genesis approach shows that there is an interaction between conceptual understanding and the use of ICT tools, considered as mediators of human behaviour and learning (Artigue 2002; Morera et al. 2012). Specifically, technological mediation is at the heart of the relation between the tool or artefact and the user and it may happen that certain features or uses of the tool transform user understanding. This is the process whereby the artefact becomes an instrument for the user and the process is called instrumental genesis (Guin and Trouche 1999). Therefore, students have to perceive affordances (Gibson 1966) of technological environments and take advantage of them to be able to understand the task properly and act subsequently (Brown 2015).

Moreover, different types of technological supports impact different phases of the modelling cycle (Greefrath 2011). Despite this, those that have received more attention in the field of mathematics education are those that allow the treatment of the data obtained (Geiger 2011) instead of those in which data are captured through the use of technology, which will be the focus in our study.

\subsection{The Research Study}

In the present study, we adopted the theoretical and methodological framework for research in mathematics education of Local Theoretical Models (LTMs), developed by Filloy et al. (2008). In this framework, competence, cognitive, teaching and communication models (p. 34) are developed to make sense of the phenomena that occur in the teaching and learning processes of specific mathematical content with a particular group of students in a specific setting. The model is thus local and serves to give an account of what is observed on the basis that "if things were as characterized by the model then the phenomena would be as observed" (Puig 2010, p. 3). The LTM is descriptive, explanatory and predictive in nature but does not rule out other descriptions, explanations or predictions of the same observed phenomena (Puig 2010) but is adequate in the particular setting.

In our case, teaching material was designed to study linear and quadratic functions through the use of electronic tablets and the mathematical modelling of two different physical phenomena. The study presented here is part of a more general one in which students' performances are analysed from different points of view when they are working with this teaching material. In particular, what we show here is the effect of using a specific technological tool during the mathematisation of the phenomena on students' performances. Specifically, our research aim will be to answer the following question: What is the effect of the decisions that students make during the mathematisation of the phenomena conditioned by Video Physics ${ }^{\circledR}$ app on the interpretation of the characteristics of the models? 
Another part of the general study that complements the research presented here can be found in Ortega and Puig (2017). In that chapter, the influence of a previous study of the qualitative properties of phenomena and families of functions on students' performances is analysed.

\subsubsection{Participants and Teaching Methodology}

We conducted our study at two different moments in our materials design trajectory, thus we implemented the teaching material with, and collected data from, two different groups of students. These were Year 11 upper secondary school students (16-years-old) with similar characteristics. They were intact class groups of 16 students each: 10 girls and 6 boys in the group in which the first material to study the quadratic function was implemented and 7 girls and 9 boys in the group in which material to study the linear function was implemented. Students of both groups did not have any previous experience in solving modelling problems or studying physical phenomena as families of functions from a mathematical perspective (although students of both groups had prior knowledge of Physical laws that describe the kind of relation between the variables studied). However, both groups had studied linear and quadratic functions before but not by using electronic tablets.

The teaching experiments had two different parts: classroom lessons and interviews. Both classroom lesson implementations were for two sessions of $55 \mathrm{~min}$ each with experiments with actual phenomena and the collection of data using electronic tablet apps occurring during this time. Students also completed worksheets. At the end of both experiments, 2 groups of 2 students were selected based on the results obtained after analysing their answers to participate in an interview. The interview had a dual purpose. The first was to identify students' decisions made during mathematisation influenced by the features of the Video Physics ${ }^{\circledR}$ app in the interpretation of the model. The second purpose was to guide the students to become aware of their misconceptions related to their performances during these phases and to overcome them. For classroom lessons, the teacher kept a diary and all sessions were videoand audio-recorded.

The students worked in groups of two (designated A1-A8 for Experiment A and B1-B8 for Experiment B) during both teaching experiments, except when they had to carry out and record the experiments. The purpose of working in pairs was to encourage the verbalization of what they were doing, thinking or wanting to do (Schoenfeld 1985) because, although this does not allow us to know the cognitive processes of the students when they are dealing with a task, at least it is possible for us to obtain the data of the explanations that they are forced to give in a collaborative environment. The teacher was the same during classroom lessons and interviews, not the usual teacher of the groups but one of the researchers. She provided minimal help during the lessons in order to allow the students to work at their own pace and avoid not being influenced by other students' ideas. However, during the interviews 
the teacher had an essential role: to guide the students through the questions and to provide suggestions for them to overcome the difficulties observed.

\subsubsection{Data Analysis and Research Method}

Due to the characteristics of the Local Theoretical Models, the methodology used for the analysis of the data will be those commonly used in this framework. This methodology will be described distinguishing between the data from student performances during the classroom lessons and the interviews.

The analysis of the data from classroom sessions started by extracting the data from worksheets, the teacher's diary, iPads and video cameras and relating them in a coherent way by describing students' performances. Next, similar types of students' performances were searched according to the noteworthy aspects of each item, grouped and described in detail. Finally, cognitive tendencies in students' performances with regard to the research aim were identified and described.

For the analysis of the interviews, firstly a written protocol was elaborated. Transcriptions of the interviews were included in the protocol as well as description of the students' gestures and performances when using specific apps on iPads, accompanied by images of written answers and screenshots of videos and tablet screens. Secondly, comments to give meaning to students' performances were added to the written protocol. Afterwards, these comments were organised by undertaking a rational reconstruction (Puig 1996), that consists of a narration, based on the students' performances, with the purpose of making sense of the teaching-learning situation. In this narration, it is assumed that all students' performances have a rational and consistent base that justifies them. Next, cognitive tendencies regarding the research aim were identified. Finally, results from the study of the group during classroom lessons and the case study were related in order to answer the research question.

Due to the characterization of model in the framework of the Local Theoretical Model, description of students' performances in both classroom lessons and interviews was based not only in describing what they did during the teaching experiments but also on making explanatory hypotheses. These explanatory hypotheses are descriptions of possible explanations for students' performances, not with the intention of asserting that current cognitive processes of students are those hypothesized but, if the cognitive processes were the ones described, the performances would be the ones we have observed. In addition, other results obtained from the data analysis process are not included here as they are not part of the study presented in this chapter.

We will now present characteristics of the design of the teaching experiments, the organization and implementations in classrooms before proceeding to the reporting of results followed by a discussion of these. 


\subsection{Design of the Teaching Experiments}

Considering the distinction between modelling as content in its own right and as a vehicle for teaching mathematics in educational settings (Julie and Mudaly 2007; Gravemeijer and Doorman 1999), we designed two tasks considering modelling as a vehicle for the development of particular mathematical content: the characteristics of the families of linear and quadratic functions.

The two tasks studied were phenomena widely studied by classical physics and concerned the use of real data, which would be directly taken into the classroom by the students using iPads. In the first teaching experiment (A), the phenomenon studied was the relation between the time and the height of a ball dropped from a certain height restricted to the first rebound and the subsequent drop of the ball, that is, from the moment that the ball touches the ground for the first time until it touches it again. Since this phenomenon is a uniformly accelerated rectilinear motion, it can be described by one of the kinematics laws of Newton, $y(t)=y_{0}+v_{0} \cdot\left(t-t_{0}\right)+1 / 2$ $\cdot g \cdot\left(t-t_{0}\right)^{2}$ where $y$ is the distance travelled by the ball, $t$ is the time in each instant and $y_{0}, v_{0}$ (null in our case), $g$ and $t_{0}$ are constants. Therefore, it can be represented by a quadratic function where $t$ is the independent variable and $y$ the dependent one. In the second teaching experiment (B), the physical phenomenon was the relation between the lengthening of a spring (in the form of a slinky) and the number of marbles introduced into a glass that hangs from it. Since the phenomenon is asked to be studied only in the elastic zone of the spring, we can consider that the function that approximates this relation is a linear function. Specifically, as the force of the spring will be equivalent to the force of the weight of the marbles and considering Hooke's law, we will obtain that $k \cdot y=N \cdot m_{i} \cdot g$, where $k$ is the elastic constant, $y$ the spring elongation, $N$ the number of marbles, $m_{i}$ the mass of a marble and $g$ the acceleration of gravity. Therefore, now the relation that has to be studied is the one between $y$ and $N$, isolating the dependent variable we obtain that the function that describes the phenomenon in the studied area is $y(N)=\left(m_{i} \cdot g\right) / k \cdot N$. Although the theoretical reasons that prove the type of function that better describes the phenomena comes from Physics laws, during the teaching experiments this is not mentioned to the students.

In general terms, the questions of the experiments can be divided into three types of sets of questions that would be implemented in the order presented here. The first question type was designed to make an initial analysis of the qualitative properties of the phenomena and the families of functions, following the idea first developed in Puig and Monzó (2013) and subsequently applied in Ortega and Puig (2017) that the incorporation of this type of question can help students manage and control the modelling process. The second type of questions, which were called instructional questions, was intended to give students guidelines on how to conduct the experiments and how to obtain the data. Finally, the third question type was intended to guide the students to find a function that fits the data and, to work on specific aspects of the function obtained and to interpret some of its characteristics in relation to the experiment to verify suitability and validity. In Ortega and Puig (2015), further details 
of the design of the teaching material and the specific questions for the experiment of the bounce of a ball are given.

However, although in general the characteristics of both designs are similar, they differ in three main aspects. First, questions formulated in each teaching experiment were slightly different. This was because teaching experiment B was conducted after A, after considering how the characteristics of the design of teaching material used in A could be improved. Second, the way of obtaining the variables to study in each experiment was also different. Whereas in experiment A both variables were given directly by the app, in experiment B students had to construct one variable (number of marbles) and transform the values provided by the app for the other (to obtain a positive lengthening that initially is zero). Third, the way to obtain the functions, and consequently the apps used in each experiment, differ as well. While in experiment A students only had to choose the formula of the family of functions so that the Data Analysis ${ }^{\circledR}$ app provided the specific function, in experiment B students had to find the function by handling the values for the parameters in the formula and noticing the graphic transformations related to them in Desmos ${ }^{\circledR}$ app.

\subsection{Implementation of Teaching Experiments}

Although the teaching material was implemented at different times and with different groups of students, both teaching experiments took place in the students' usual classroom and were carried out during two sessions of 55 min each, not including the interviews.

In the first session of each experiment, the students had to answer the first set of questions and to obtain the data from real experiments following the second set of questions. In particular, they were asked to analyse the qualitative properties of the phenomenon and the families of functions sketching the graph that they expected to represent the phenomenon and choosing the algebraic expression of the family of functions that they thought would describe better the phenomenon from a given list. Next, they had to perform the experiments in the classroom recording with a video following the instructions given in the second set of questions in order to obtain the coordinates of the points that showed the relation studied in each case using the app Video Physics ${ }^{\circledR}$. For the first experiment, the students had to stand on a chair and drop a ball. In the second experiment, the students from the other group had to place each end of a wooden strip over a table and then hang a spring from it with a plastic cup on the end of the spring, where up to 8 marbles would be introduced gently. Once they had video-recorded the experiments with an iPad, they had to send the video to the rest of the devices so that the students could continue working in pairs. Following this, they had to obtain the values for the variables on the trajectory of the moving object using the following actions in the app: (a) setting the referential axes in one of the photographs (Fig. 9.1a, b) locating a referential measure by marking a segment in one of the photographs and introducing its real value into the app (Fig. 9.1b, c) marking a point on the object that is changing its trajectory in each photograph of 
(a)

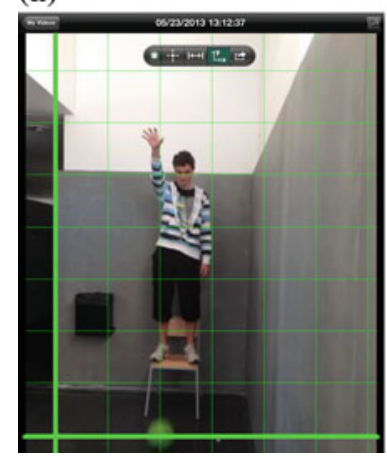

(b)

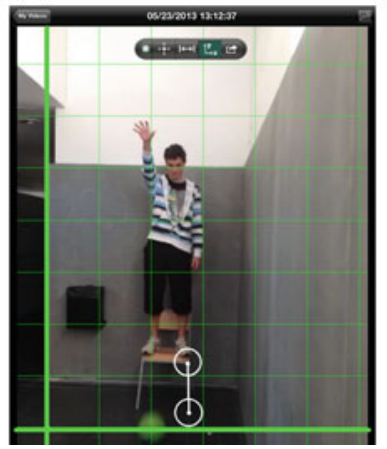

(c)

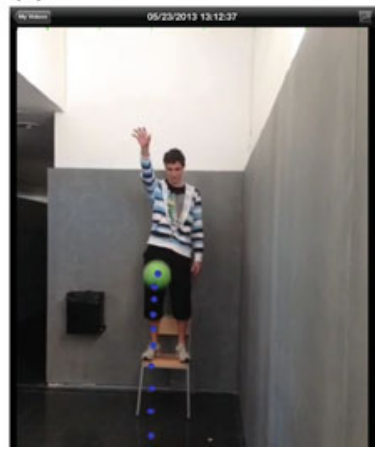

Fig. 9.1 Sequence of screenshots $\mathbf{a}-\mathbf{c}$ of the process of obtaining data in the first experiment

the video, that is, on the ball in experiment $A$ and on the end of the spring or on the plastic cup in experiment B (Fig. 9.1c). It should be noted that what the app does next is to show different graphs relating the variables time, distance of the points to the $x$-axis and distance of the points to the $y$-axis on the grid overlaying the video. Then, obtaining the values of these variables separated by columns in an Excel file has to be requested of the app, so the students can construct the coordinates of the points that describe the relation studied in each case. However, whereas in experiment A the coordinates can be obtained directly because both the time and the height of the ball are variables provided by the app, this does not happen in experiment $B$. In $\mathrm{B}$, every point has to have as its first coordinate the number of marbles introduced into the plastic cup, which can be determined easily, and as the second coordinate the lengthening of the spring, for which values will have to be calculated adding, subtracting or multiplying by -1 one of the variables provided by the app, depending on where the students set the $x$-axis and the points.

Hence, the mathematisation of the phenomenon is conditioned by the characteristics of the app and the possibilities that it offers to the students. Moreover, the way in which students take references will affect the values that variables will take and, consequently, the functions. Therefore, students will have to be conscious of how they take references and how the app works, that is, the technological tool should become an instrument for the students (Guin and Trouche 1999).

During the second session, the students had to answer the last set of questions. In particular, they had to find the algebraic expression of the function that better described the phenomenon recorded. For that purpose, in experiment A, the students had to introduce the coordinates of the points obtained with Video Physics ${ }^{\circledR}$ into the app Data Analysis ${ }^{\circledR}$. Then, they had to choose a formula of the family of functions that fitted better to the points from a list of options given by the app, which provided them with the concrete formula and the numeric values for the parameters. However, in experiment B the students were asked to copy the points to the app Desmos ${ }^{\circledR}$ and try to fit a graph to them handling the values for the parameters of the formula of the 
family of functions that they thought represented the experiment. For this, we would require the students not only to obtain the formula by themselves, but also to give meaning to the parameters of the family of functions $y=m x+n$ where $m$ and $n$ take real values for the particular experiment.

Following the experiments, students had to answer some questions to guide them through the interpretation of the model in relationship to the real phenomenon and the model validation. Firstly, the students were asked to (a) calculate some images of the function and (b) explain if doing this calculation made sense, where they were pushed to interpret its meaning in the real world. They had to realize that, although the domains of both functions are all the real numbers, the functions only make sense in the interval of values for which the phenomena studied are defined: just during the first vertical rebound and fall, or until the eighth marble is introduced into the plastic cup. For that reason, some of the points, for which images had to be calculated, were out of the interval and students were asked, among other questions, to explain why the answers did not show what really happened. Finally, students had to answer further questions by interpreting the peculiarities of the function (using the graph, the concrete algebraic expression or the coordinates of the points) comparing it to concrete characteristics of the experiment conducted in the classroom. In particular, in experiment A they were asked to calculate the values of time when the ball touched the ground and the values of time when it reached the maximum height. In experiment $\mathrm{B}$, they had to calculate the lengthening of the spring when 4 marbles had been introduced into the plastic cup, the minimum length of the spring during the experiment, and the distance between the plastic cup and the ground. Finally, they had to explain how the function would change if they had to study the distance between the cup and the ground instead of the lengthening of the spring. To answer all these questions students were allowed to use the app Free Graphing Calculator ${ }^{\circledR}$, which made it possible to represent functions graphically and let students calculate images of the function, amongst other possibilities.

After these classroom lessons, 2 groups of 2 students from each experiment were selected to participate in an interview, conducted by the teacher-researcher in one 55 min session per group. In the interview, students' reasons for choosing the references were identified and also the way they conceived of the variables during the interpretation of the phenomena in relation to the experiment, as will be shown in Sect. 9.6.1 and 9.6.2. In addition, they were guided to realize their misconceptions through teacher questions and suggestions.

\subsection{Results}

In the following subsections, the results of the analysis of the data will be presented in detail. Firstly, we will show the way in which the students took the references in the Video Physics ${ }^{\circledR}$ app during the mathematisation of the phenomena and what they conceived as the variables for each experiment. Secondly, we will describe how they interpreted the characteristics of the model: basing their answers in their prior 


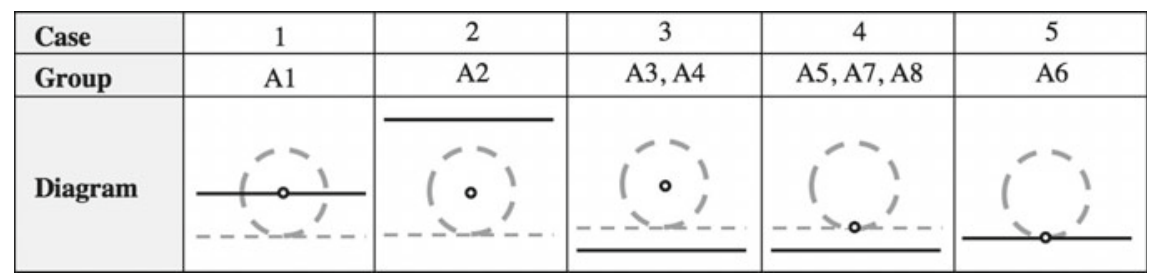

Fig. 9.2 Different schemes for establishing references in the ball experiment

conceptions instead of the way in which they had taken the references in Video Physics ${ }^{\circledR}$.

\subsubsection{Choosing References in Video Physics ${ }^{\circledR}$}

As noted previously, the characteristics of the technological tool used, the Video Physics ${ }^{\circledR}$ app, required students to choose a reference during the mathematisation, which is given by the combination of two factors: the position in which the axes have been set on the image and the position of the points marked. Therefore, the variables affected in each experiment by the way in which references are taken will be "height" (experiment A) and "lengthening" (experiment B). In particular, the significant references in both cases are the $x$-axis and the points marked.

For that reason, in experiment $\mathrm{A}$, we focused on analysing the photograph of the video in which the ball touches the ground for the first time, where it is possible to observe both the axes and the first point marked. When categorizing the responses, we observed that students set the $x$-axis in different positions with respect to the ball: below it, above it and at the same height. On the other hand, they marked the points that showed the trajectory of the ball in three different spots: at the centre, at the top or at the bottom. Avoiding duplicates and reducing equivalent options we obtained 5 different cases as shown in Fig. 9.2, where the large dashed circle represents the ball and the dashed line the ground, the small circle represents the first point marked and the black line the $x$-axis. The high number of different cases is due to the application not providing any limitations when setting references.

It is important to note that some features of the diagrams of the different responses have been simplified as they are two-dimensional drawings which represent photographs of a three-dimensional space. In these diagrams, "the ground" has been represented as the horizontal line placed at the lowest part of the ball, which has been done taking into account the students' conceptions observed both in their answers and during the interviews. Considering this is important in understanding the students' responses during the interpretation of the model.

Moreover, most of the students placed the referential axis taking into account "the ground" during the selection of references, since it is usually taken as the reference. Two categories can be distinguished: the students who placed the $x$-axis at the ground 


\begin{tabular}{|c|c|c|c|c|c|}
\hline Case & 1 & 2 & 3 & 4 & 5 \\
\hline Group & B1 & B2 & B3, B4 & B5, B6, B8 & B7 \\
\hline Diagram & 作 & & & 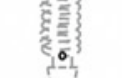 & 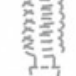 \\
\hline $\begin{array}{l}\text { Kind of } \\
\text { variable } \\
\text { used }\end{array}$ & $L+l_{s}$ & $-1 \cdot\left(L+l_{c}+l_{s}\right)$ & $-1 \cdot L$ & $d_{p, x}-L$ & $d_{p, x}-L$ \\
\hline
\end{tabular}

Fig. 9.3 Different schemes for establishing references in the spring experiment

or close to it (groups A3, A4 and A5) and the ones who placed it exactly at the chair seat where the student was standing and from which he/she dropped the ball (group A2). The students who performed as in case 1 did not make reference to the ground and they explained during the interviews that they set the referential axis in that position (see Fig. 9.2) because it was at the same height as the first point marked, therefore "the height will be zero", focusing only on the point and ignoring the rest of the elements. Therefore, it is already possible to see a certain tendency to view "the ground" as reference for variable height during the mathematisation phase because they want the height of the ball at ground level to be zero and positive above it, although only students of case 5 actually did this.

On the other hand, with regard to experiment $\mathrm{B}$, we analysed the photograph of the video in which the students marked the first point, that is when no marbles were introduced as yet (or, in the case of the students who did not mark a point when the cup was empty, the photograph where just one marble was introduced). In this case, they marked the points that showed how the length of the spring would change in two different places: in the lower part of the spring and in the bottom of the cup. They set the $x$-axis in different positions: just in the wooden strip, in the lower part of the spring, in the bottom of the cup, just in the last point marked and on the ground (at the end of the table legs). A classification of how students took the references is shown in Fig. 9.3. In the diagrams, the spring and the plastic cup are represented with dashed grey lines, the $x$-axis by a black straight line and the first point marked by a small black circle.

After observing the way the students took the references in the different photographs, we analysed how they obtained the coordinates of the points. In relation to the number of marbles introduced into the cup, all students were consistent in their answers: if they marked the first point when the cup was empty, they wrote 0 as the first coordinate of the first point and if they did it when the cup contained one marble, they wrote 1 . For the lengthening of the spring, most of the students considered the variable that gave the distance between the points marked and the $x$-axis, which was provided directly by the app itself, and they did not make any kind of calculation to ensure it was positive and initially zero. Only the students of group B1 changed the sign of the values that such a variable takes to obtain positive values for the lengthening of the spring, although they did not take into account that doing so 
5. Respon les següents qủestions. Pots utilitzar I'aplicació Free GraClac.
a) Quina és, llavors, la distància de la pilota al terra quan $x=0,76$ ? $f(0,76)=-0,2038$
b) I quan $x=1,1$ ? $f(1,1)=1,18$
c) I quan $x=0,11$ ? $f(0,11)=-6,38855$
d) I quan $x=100$ ? $f(100)=-53577,895$

Fig. 9.4 Students' answers (group A2) for values of the function at various values of $x$ [Translation: 5. Answer the following questions. Free GraCalc app can be used. (a) What is the distance of the ball to the ground when $x=0.76 ? f(0.76)=$; (b) And when $x=1.1 ? f(1.1)=$; (c) And when $x=$ 0.11 ? $\mathrm{f}(0.11)=$; (d) And when $x=100 ? f(100)=$.]

was not enough to obtain the lengthening of the spring because, this way, they were also considering its initial length. The kind of variables considered for the second coordinate of the points in each case is also shown in Fig. 9.3. In the formulas, $L$ represents the lengthening of the spring, $l_{s}$ the initial spring length, $l_{c}$ the length of the plastic cup and $d_{p, x}$ the distance between the first point marked and the $x$-axis. Therefore, no student actually took the lengthening as a variable.

\subsubsection{Interpretation of the Models}

During interpretation of the model in experiment A, all students considered that the height of the ball on the ground is exactly zero and it took positive values above it, regardless of how they had taken references with the app. In particular, students who took the references as in case 2 (see Fig. 9.2) should have considered the possibility of finding negative values for height. However, they did not conceive it this way. For students of group A2 the ball touched the ground at 0.718 and at $1.88 \mathrm{~s}$ when the height of the ball was $-0.46 \mathrm{~m}$ because they set the $x$ axis at the chair seat. So, when they calculated the height of the ball at $0.76 \mathrm{~s}$, they obtained a negative value (see Fig. 9.4). Nevertheless, in question 6 they explained that none of the negative values made sense because obtaining negative values meant "there is no ground and the ball continues falling down", as they confirmed during the interview. Hence, they attributed the obtaining of negative values to the ball being below the level of the ground, which implies that they were considering the ground as the reference. Therefore, the negative values of the images caught the students' attention more than the fact that there were points out of the interval where the function was defined in relation to the phenomenon, even when one of the points $(f(0.76)=-0.2038)$ would have made sense for their experiment. This fact explains how strong their conception was about the ground being the reference and how unfamiliar they were with interpreting mathematical results in real terms.

Otherwise, students who took the references as in cases 3 and 4 (Fig. 9.2) obtained the height of the ball at the ground is not exactly zero. However, all students considered the ground as the reference during the interpretation of their model. In particular, 


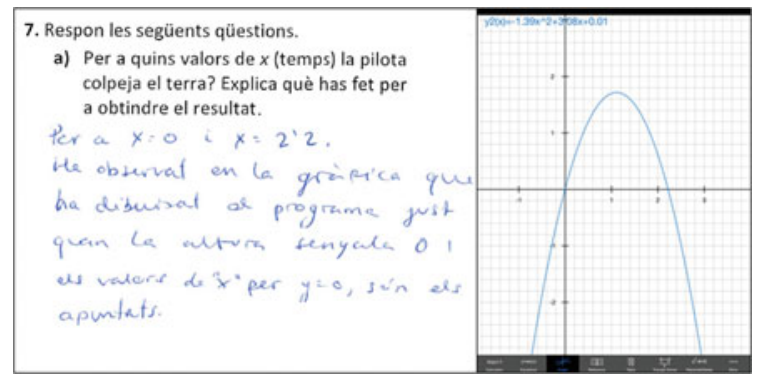

Fig. 9.5 Students' answers (group A5) at question 7 (left) and screenshot of graph (right) [Translation: 5. Answer the following questions. (a) At which values of $x$ (time) does the ball touch the ground? Explain how you got the solution. "For $x=0$ and $x=2.2$. We have observed the graph drawn by the program just when the height is 0 and values of $x$ for $y=0$ are the ones we have written."]

when they were asked to calculate the time when the ball was on the ground, groups A5 and A8 made $y=0$ and solved the resulting equation and groups A3, A4 and A7 looked at the values of $x$ where the graph cut the $x$-axis, all considering the height of the ball at ground level as zero.

Finally, although the values for the height of the ball would always be positive and zero on the ground for the students of cases 1 and 5 , only case 5 students took the floor as reference (see Fig. 9.2). In case 1, the students of group A1 set the $x$-axis in the first point marked "[...] as if the ball was half above and half below the ground", as they confirmed after becoming aware of it during the interview. Therefore, the height of the ball at ground level would actually be negative. In relation to the students of case 5, despite having taken the ground as a reference, group A5 obtained that the height of the ball on the ground was not exactly zero due to the lack of precision when taking references in Video Physics ${ }^{\circledR}$. However, when the students were asked to calculate the values of time when the ball touched the ground in question 7, they answered that it is "when $x=0$ and $y=2.2$ " because these are "the values of $x$ when $y=0$ " (see Fig. 9.5) considering the height to be exactly zero, not using the data of their own experiment.

In relation to the interpretation of the characteristics of the function in experiment $\mathrm{B}$, it was observed that students considered lengthening as a variable that always takes positive values and it was zero initially when no marbles were in the cup, independent of the kind of variable used for the lengthening and how the references were taken.

Specifically, students from cases 2 and 3 should have considered the possibility of obtaining negative values for the lengthening of the spring according to the way they defined the variable. Nevertheless, no student saw it that way. Students from group B3 calculated some images of the function and explained that $f(4)=-0.023$ made no sense because "lengthening cannot be negative". Students of groups B2 and B4 also indicated that obtaining negative values made no sense, although they did not explain why. However, when they were asked to explain what the calculated function 


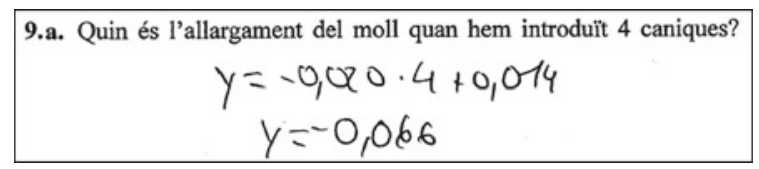

Fig. 9.6 Students' answer (group B5) for the lengthening when 4 marbles are introduced [Translation: 9.a. What is the lengthening of the spring when we have introduced 4 marbles into the cup? "y $=-0.020 \cdot 4+0.014 "$, " $\mathrm{y}=-0.066 "$.

represented, they explicitly indicated that the function showed the relation between number of marbles and lengthening of a spring. Therefore, they were considering that it was not possible to obtain negative values because lengthening cannot be negative.

We also noticed that most students assumed that initial lengthening was zero, despite taking references in a way that did not lead to this. Only those in case 3 could consider that the lengthening of the spring was zero at the beginning but also students in cases 1, 2, 4 and 5 conceived it in that way. For example, students from group B1 (case 1) considered an initial length for the lengthening because they set the axis just in the wooden strip and marked the points in the lower part of the spring. However, they said that the function showed the relation between the number of marbles and the lengthening of the spring, which "is zero because there aren't marbles in the glass" as they indicated during the interview.

Finally, despite no student actually taking the lengthening of the spring as a variable, understood as having a positive value that was zero initially, we thought that maybe they could have considered "lengthening" as another variable and still be coherent with it. In particular, during the mathematisation students from cases 1 and 2 considered the lengthening plus a certain length, students from case 3 a negative lengthening and students from cases 4 and 5 the distance to the ground or the last point marked (see Fig. 9.3). However, no student was coherent with these considerations during the interpretation. For instance, students of group B5 used their function to find the lengthening of the spring for 4 marbles (see Fig. 9.6), which actually gave the distance between the 4th point marked and the $x$-axis. Nevertheless, they conceived of lengthening as a positive magnitude that was 0 at the beginning because when we asked them during interview to explain why they had used a linear function to fit the data, they said that it was because it "gives the lengthening of the spring because the more marbles the larger numbers and the slope is positive". That is, they conceived that their function provided the "lengthening" per se, not the variable that they had considered.

\subsection{Discussion and Conclusions}

As was noted previously, more studies in which the interplay of technology is analysed in modelling situations are needed (Grigoraş et al. 2011), especially studies in which data are captured through the use of technology. In this study we have anal- 
ysed how the way in which students take and process data during the mathematisation of phenomena using the Video Physics ${ }^{\circledR}$ app influenced students' performances. In particular, Video Physics ${ }^{\circledR}$ app gives students the liberty of establishing a reference system during the mathematisation of the phenomena, which makes them have to understand the task in a certain way (Artigue 2002) to be coherent with their decisions during the whole activity and, in particular, during the interpretation of the model.

However, we have found that students interpret the function obtained in relation to their prior conceptions about the values involved in the variables of each function, not basing their interpretation on how they have taken the references. In experiment A, we observed that students had a deep-rooted idea that they should use the ground as reference, which comes from most previous school activities, and the use of the technological tool did not change this. In fact, although most of the students in our study chose references different from the ground when using the Video Physics ${ }^{\circledR}$ app, all ended up considering the ground as a reference during the interpretation phase of the model. In particular, their interpretations were based on the height of the ball not taking negative values and height being exactly zero on the ground, so they were not consistent with interpreting what they did during the mathematisation. In experiment $\mathrm{B}$, students with similar educational backgrounds and age did not perform coherently either. Specifically, during the mathematisation phase no student conceived the variable "lengthening of the spring" as it is defined in Physics: as the magnitude that describes the difference between the length of an elastic object at a given moment and its length when it is not stretched, so it always will take positive or zero values. Nevertheless, all referred to the "lengthening" during the interpretation phase. In addition, they could have considered "lengthening as another variable" and still be coherent, which would be correct from the perspective we took in these tasks in which phenomena have to be organised by mathematical content and processes (Freudenthal 1983). However, they used lengthening in the sense of a positive variable which is zero initially.

Therefore, it seems that in these cases students have not perceived what Gibson (1966) called affordances in general terms in Video Physics ${ }^{\circledR}$ app related to the freedom of taking references and these have become an added difficulty for students rather than a positive aspect. They do not seem to be aware that the way in which they took references influenced the kind of data they obtained because they did not pay enough attention when taking references during mathematisation, nor the way in which the reference taken influenced their data. In addition, this lack of coherence within the students' performances in either circumstances can probably be attributed to being a consequence of the students not being used to being asked previously in their educational experiences to set references nor to interpret mathematical results in real terms.

Hence, technological tools can be useful to require students to pay attention to aspects that normally are set for them and to make decisions that they are not used to doing. Moreover, students need experience in doing this for themselves and they should not be relieved of facing this kind of problematic by teachers doing this for them in task instructions or technological tools being set so they would have no 
access to aspects like this. However, it is necessary to emphasize the importance of the role of the teacher in the classroom to prompt students to notice this type of situation because, as we have seen in this study, at least the first few times they tackle this kind of task, they might not be aware that they have to pay attention in certain aspects, which will have decisive consequences during the whole task.

Consequently, mathematics lessons should include tasks in which the use of technological tools ensure students reflect on their performances and the decisions they make, especially when they are working on tasks that require relating the real world and mathematics, with which they are not used to dealing. Reflection on actions with tools and the consequences for decision making are critical to developing modelling competency in real-world tasks with technological tools where such tools are used in a meaningful manner.

Acknowledgements This study has been funded by the research programs EDU2012-35638 (MINECO), EDU2015-69731-R (MINECO/FEDER) and GVPROMETEO2016-143 (Conselleria d'Educació, Investigació, Cultura i Esport de la Generalitat Valenciana) and by Ph.D. grant BES2013-063826 (MINECO).

\section{References}

Artigue, M. (2002). Learning mathematics in a CAS environment: The genesis of a reflection about instrumentation and the dialectics between technical and conceptual work. International Journal of Computers for Mathematical Learning, 7(3), 245-274.

Brown, J. P. (2015). Visualisation tactics for solving real world tasks. In G. A. Stillman, W. Blum, \& M. S. Biembengut (Eds.), Mathematical modelling in education research and practice: Cultural, social and cognitive influences (pp. 431-442). Cham: Springer.

Duschl, R. A., \& Grandy, R. E. (2012). Two views about explicitly teaching nature of science. Science \& Education, 22(9), 2109-2139.

Filloy, E., Puig, L., \& Rojano, T. (2008). Educational algebra. A theoretical and empirical approach. New York: Springer.

Freudenthal, H. (1961). The concept and the role of the model in mathematics and natural and social sciences. Dordrecht: Reidel.

Freudenthal, H. (1983). Didactical phenomenology of mathematical structures. Dordrecht: Reidel.

Geiger, V. (2011). Factors affecting teachers' adoption of innovative practices with technology and mathematical modelling. In G. Kaiser, W. Blum, R. Borromeo Ferri, \& G. Stillman (Eds.), Trends in teaching and learning of mathematical modelling (pp. 305-314). Dordrecht: Springer.

Geiger, V., Faragher, R., \& Goos, M. (2010). CAS-enabled technologies as 'agents provocateur, in teaching and learning mathematical modelling in secondary classrooms'. Mathematics Education Research Journal, 22(2), 48-68.

Gibson, J. J. (1966). The senses considered as perceptual systems. Boston: Houghton Mifflin.

Gravemeijer, K., \& Doorman, M. (1999). Context problems in realistic mathematics education: A calculus course as an example. Educational Studies in Mathematics, 39(1-3), 111-129.

Greefrath, G. (2011). Using technologies: New possibilities of teaching and learning modelling-Overview. In G. Kaiser, W. Blum, R. Borromeo Ferri, \& G. Stillman (Eds.), Trends in teaching and learning of mathematical modelling (pp. 301-304). Dordrecht: Springer.

Greefrath, G., \& Rieß, M. (2013). Reality based test tasks with digital tools at lower secondary. In G. A. Stillman, G. Kaiser, W. Blum, \& J. P. Brown (Eds.), Teaching mathematical modelling: Connecting to research and practice (pp. 445-456). Dordrecht: Springer. 
Greefrath, G., \& Siller, H-S. (2017). Modelling and simulation with the help of digital tools. In G. A. Stillman, W. Blum, \& G. Kaiser (Eds.), Mathematical modelling and applications: Crossing and researching boundaries in mathematics education (pp. 529-539). Cham: Springer.

Grigoraş, R., Garcia, F. J., \& Halverscheid, S. (2011). Examining mathematising activities in modelling tasks with a hidden mathematical character. In G. Kaiser, W. Blum, R. Borromeo Ferri, \& G. Stillman (Eds.), Trends in teaching and learning of mathematical modelling (pp. 85-95). Dordrecht: Springer.

Guin, D., \& Trouche, L. (1999). The complex process of converting tools into mathematical instruments: The case of calculators. International Journal of Computers for Mathematical Learning, 3(3), 195-227.

Henn, H.-W. (2007). Modelling pedagogy-Overview. In W. Blum, P. Galbraith, H.-W. Henn, \& M. Niss (Eds.), Modelling and applications in mathematics education: The 14th ICMI study (pp. 321-324). New York: Springer.

Julie, C., \& Mudaly, V. (2007). Mathematical modelling of social issues in school mathematics in South Africa. In W. Blum, P. Galbraith, H.-W. Henn, \& M. Niss (Eds.), Modelling and applications in mathematics education: The 14th ICMI study (pp. 503-510). New York: Springer.

Morera, L., Fortuny, J. M., \& Planas, N. (2012). Momentos clave en el aprendizaje de isometrías en un entorno colaborativo y tecnológico. Enseñanza de las Ciencias, 30(1), 143-154.

Oliveira, A. M. P., \& Barbosa, J. C. (2013). Mathematical modelling, mathematical content and tensions in discourses. In G. A. Stillman, G. Kaiser, W. Blum, \& J. P. Brown (Eds.), Teaching mathematical modelling: Connecting to research and practice (pp. 67-76). Dordrecht: Springer.

Ortega, M., \& Puig, L. (2015). Modelización de una situación real con tabletas: el experimento de la pelota. Modelling in Science Education and Learning, 8(2), 67-78.

Ortega, M., \& Puig, L. (2017). Using modelling and tablets in the classroom to learn quadratic functions. In G. A. Stillman, W. Blum, \& G. Kaiser (Eds.), Mathematical modelling and applications: Crossing and researching boundaries in mathematics education (pp. 565-576). Cham: Springer.

Osborne, J. (2014). Teaching scientific practices: Meeting the challenge of change. Journal of Science Teacher Education, 25(2), 177-196.

Perrenet, J., \& Zwaneveld, B. (2012). The many faces of the mathematical modeling cycle. Journal of Mathematical Modelling and Application, 1(6), 3-21.

Pollak, H. O. (1979). The interaction between mathematics and other school subjects. In UNESCO (Ed.), New trends in mathematics teaching IV (pp. 232-248). Paris: UNESCO.

Puig, L. (1996). Elementos de resolución de problemas. Comares: Granada.

Puig, L. (2010). Researching (algebraic) problem solving from the perspective of local theoretical models. Procedia Social and Behavioral Sciences, 8, 3-16.

Puig, L., \& Monzó, O. (2013). Fenómenos y ajustes. Un modelo de enseñanza del proceso de modelización y los conceptos de parámetro y familia de funciones. En T. Rojano (Ed.), Las tecnologías digitales en la enseñanza de las matemáticas, 9-35. México: Trillas.

Sala, G., Font, V., Giménez, J., \& Barquero, B. (2017). Inquiry and modelling in a real archaeological context. In G. A. Stillman. W. Blum, \& G. Kaiser (Eds.), Mathematical modelling and applications: Crossing and researching boundaries in mathematics education (pp. 325-335). Cham: Springer.

Schoenfeld, A. (1985). Mathematical problem solving. Orlando: Academic Press.

Stillman, G. (2007). Implementation case study: Sustaining curriculum change. In W. Blum, P. Galbraith, H.-W. Henn, \& M. Niss (Eds.), Modelling and applications in mathematics education: The 14th ICMI study (pp. 497-502). New York: Springer. 
Open Access This chapter is licensed under the terms of the Creative Commons Attribution 4.0 International License (http://creativecommons.org/licenses/by/4.0/), which permits use, sharing, adaptation, distribution and reproduction in any medium or format, as long as you give appropriate credit to the original author(s) and the source, provide a link to the Creative Commons license and indicate if changes were made.

The images or other third party material in this chapter are included in the chapter's Creative Commons license, unless indicated otherwise in a credit line to the material. If material is not included in the chapter's Creative Commons license and your intended use is not permitted by statutory regulation or exceeds the permitted use, you will need to obtain permission directly from the copyright holder.

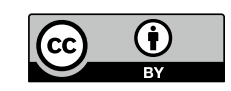

